paediatrics. It will give the trained paediatric surgeon insight into some alternative procedures, but the book lacks guidance on some of the less common variations. Undoubtedly the book has a place on the shelves of children's hospitals and paediatric departments as a reference book for paediatricians.

Perspectives in Coeliac Disease. Proceedings of the 3rd Symposium on Coeliac Disease, September 1977

Edited by B. McNicholl, C. F. McCarthy \& P. F. FotTrell. Pp. 504, illustrated. Lancaster: MTP Press, 1978. $£ 14.95$.

The pathogenesis of mucosal damage in coeliac disease remains an enigma. This book is a compilation of papers presented at the Third International Coeliac Symposium which was held in Galway in September 1977 to provide a forum for debate on many aspects of research into the disorder. The central themes are the characterization of the toxic fraction of gluten, and the elucidation of its mode of action on the intestinal mucosa of sensitive individuals. There are 2 useful background reviews of the biochemical and immunological theories of gluten-sensitive enteropathies.

Much of the work discussed consolidates and develops the ideas of the Second Coeliac Symposium held in Leiden in 1974. The Galway group's evidence that removal of the carbohydrate moiety from gliadin abolishes toxicity is presented. It clearly highlights the problems of such studies in patients, hence the continuing search for a method of fractionating gluten and identifying toxic peptides in organ culture systems. This work has now firmly relegated analysis of epithelial cell enzyme activities to the end of the book.

There are sections on genetic markers and immunology in which secondary immunological phenomena are well described. The evidence for primary involvement of immune mechanisms remains elusive. The developing area of gut hormone profiles in intestinal disorders is represented, but the authors admit that their interesting findings are likely to be secondary to mucosal damage.

Our definition of coeliac disease still depends on the response to treatment. Practical problems such as the conduct of a gluten challenge and confirmation of the diagnosis continue to exercise clinicians. Their voices are heard and some answers are given, however, this book will be of particular use to research workers in the field for whom it will be a mine of information.

\section{Price's Textbook of the Practice of Medicine}

Edited by RoNAld Bodley ScotT with 79 specialist contributors. Pp. xi +1495, illustrated. Oxford, New York, Delhi: Oxford University Press, 1978. £25.00.

Every medical practitioner, generalist or specialist, will have need of one reference textbook of medicine. Since 1922 Price has been the standard medical reference for most physicians trained in Britain and over the years its reputation has spread so that it is now an essential component of the medical library of many other doctors in the English speaking world.

In this, the 12 th edition, the type has been completely reset and the book redesigned so that it is now not only larger but almost twice as heavy as its predecessor. All the chapters have been rewritten, some in toto, some only in part, and of the 79 contributing authors 51 are newcomers to this edition.

In layout and presentation the book follows the traditional pattern. It is in 18 sections covering each of the major body systems and groups of diseases. The index is particularly clear, with major items in bold face for rapid identification.

It is difficult to find fault without carping: the book is now too heavy to be read in comfort on the lap. It could have been produced in 2 or even 3 volumes (at extra cost but probably worth it). Sections on epidemiology statistics might have been included, and possibly one on the ways in which health care is delivered-if only to remind every physician that these aspects of the practice of medicine are also important.

\section{Principles of Chest X-ray Diagnosis (4th edn)}

By George Simon. Pp. 296, illustrated. Sevenoaks: The Butterworth Group, 1978. $£ 19.00$.

The publication of the fourth edition of George Simon's well known text is unfortunately overshadowed by the recent death of the author, an outstanding figure in British Radiology. Dr Simon's texts are well known as required reading by all radiological students, and few of the present generation of British Consultant Radiologists have not benefited from them. The fourth edition is similar in layout to the previous edition but contains a number of new illustrations as well as an extensive revision of the text to incorporate new knowledge. The emphasis is on basic anatomical knowledge, the analysis and differential diagnosis of radiological abnormalities and their correlation with underlying pathology. All students of chest diseases will benefit from studying this book, whether radiologist, physician or surgeon.

\section{Textbook of Medical Treatment (14th edn)}

Edited by Stanley Alstead \& Ronald H. Girdwood. Pp. 533, illustrated. Edinburgh, London, New York: Churchill Livingstone, 1978. £14.75.

This is the fourteenth edition of a classic which first appeared in 1939 under the editorship of Dunlop, Davidson and McNee. Some 35 contributors, mostly Scottish, have made the present volume readable and up to date, and the editors have maintained a sensible balance in its 32 admirable chapters. It is clear that this edition has been pruned, so go out pesticides and industrial diseases. Not yet in are the remark able new treatments for acrodermatitis enteropathica; levamisole immunostimulation, Legionnaires' disease, Behçet's syndrome, Burkitt's lymphoma, the clinical significance of HLA and associated disorders, and the pathogenesis of clindamycin colitis. The next edition will also introduce the chemotherapy of virus infections in greater depth. But this is just quibbling, when 533 invaluable pages cost only 114.75 . A truly Scottish bargain.

Today's Treatment/2. Articles published in the British Medical Journal.

Pp. 221. London: British Medical Journal, 1977. Soft cover $£ 4$ inland; U.S. $\$ 10.00$ overseas, incl. postage.

Modern treatment is constantly changing. Therapeutic skills can only be kept up to date by keeping pace with this change. By the time many textbooks reach our bookshelves, treatments have often been revised. For this reason, the modern clinician will rely on publications such as this.

Today's Treatment contains a collection of articles published in the British Medical Journal during 1976 and 1977. These cover Endocrine and Metabolic Diseases, Diseases of the Cardiovascular System and Diseases of the Alimentary System.

It is not possible to mention all the topics but the common therapeutic problems are well covered, such as Diabetes, Angina, Hypertension and Jaundice. The reviewer was particularly pleased to see a number of the less glamorous problems so well represented. All clinicians will be only too familiar with the difficulties posed by obesity, anorexia, constipation, pain and symptoms at the menopause. At the end of most sections there is a useful list of references.

The book is intended to provide a working manual for all doctors in clinical practice and is to be highly recommended. 